\title{
Laboratory evaluation of a prospective remediation method for $\mathrm{PCB}$-contaminated paint
}

\author{
Erin K H Saitta ${ }^{1}$, Michael J Gittings², Christian Clausen', Jacqueline Quinn ${ }^{3}$ and Cherie L Yestrebsky ${ }^{1 *}$
}

\begin{abstract}
Background: Paint laden with polychlorinated biphenyls (PCBs) often acts as a point source for environmental contamination. It is advantageous to address contaminated paint before the PCBs transport to surrounding media; however, current disposal methods of painted material introduce a variety of complications. Previous work demonstrates that PCBs can be broken down at ambient temperatures and pressures through a degradation process involving magnesium metal and acidified ethanol. This report is an extension of that work by describing the development of a delivery system for said reaction in preparation for a field test. Two treatment options including the Activated Metal Treatment System (AMTS) and the Non-Metal Treatment System (NMTS) remove and degrade PCBs from painted surfaces.

Findings: AMTS decreased the Aroclor ${ }^{\circledast}$ concentration of a solution by more than $97 \%$ within 120 minutes and the Aroclor ${ }^{\oplus}$ concentration of industrial paint chips by up to $98 \%$ over three weeks. After removing up to $76 \%$ of PCBs on a painted surface after seven days, NMTS also removed trace amounts of PCBs in the paint's concrete substrate. The evaporation rate of the solvent (ethanol) from the treatment system was reduced when the application area was increased. The solvent system's ability to remove more than $90 \%$ of PCBs was maintained after losing $36 \%$ of its mass to solvent evaporation.
\end{abstract}

Conclusions: The delivery systems, AMTS and NMTS, are able to support the hydrodechlorination reaction necessary for PCB degradation and are therefore attractive options for further studies regarding the remediation of contaminated painted surfaces.

Keywords: Polychlorinated biphenyl (PCB), Remediation, Aroclor, Paint, Magnesium

\section{Findings}

Introduction

Despite regulation, PCB-contaminated materials remain prevalent in the environment including remote locations $[1,2]$. Renovations and weather conditions cause PCBcontaminated paint to flake, leading to increased concentrations in water and soil [3-5]. Once in the soil, addressing PCBs through dredging, capping and bioremediation is difficult and expensive therefore removing PCBs from painted surfaces before they enter the environment is advantageous [6]. Unless under the EPA action limit, federal law requires PCB-contaminated materials be disposed of in a limited number of licensed landfills, where they often charge by amount of material disposed [7].

\footnotetext{
* Correspondence: cherie.yestrebsky@ucf.edu

${ }^{1}$ Department of Chemistry, University of Central Florida, 4000 Central Florida Blvd, Orlando, FL 32816-2366, USA

Full list of author information is available at the end of the article
}

Many PCB-contaminated sites contain large structures with painted vertical surfaces. Remediating these sites often require the structures to be broken down and transported, an expensive process that can further contaminate the environment. Incineration of the PCB-contaminated materials can emit other toxic compounds like dibenzodioxins and dibenzofurans [8]. The PCB-contaminated dust that is produced by sandblasting has been reported to spread to surrounding surfaces and the environment [9]. Considering the issues introduced by current remediation techniques, a novel remediation option for painted structures is desired.

Previous research has shown that magnesium, carboxylic acid, and alcohol have the ability to degrade polycyclic aromatic hydrocarbons, like PCBs, through hydrodechlorination [10-12]. This report describes an extension of that research with the development of a delivery system for the reaction components creating degradation options 
for PCB-contaminated painted structures. The Activated Metal Treatment System (AMTS) and a Non-Metal Treatment System (NMTS) are formulated to be applied to painted surfaces and sealed to minimize evaporation [13]. Calcium stearate, polyethylene glycol, glycerol, and sodium polyacrylate were added to ethanol, limonene and acetic acid to create an application media viscous enough to adhere to a vertical surface. Magnesium metal in the AMTS begins degrading PCBs as they enter the system while the NMTS extracts PCBs from a surface and is subsequently combined with metal to degrade PCBs.

\section{Experimental}

\section{Aroclor $^{\circledR}$ degradation through AMTS}

A $10.0 \mu \mathrm{l}$ aliquot of $12,500 \mathrm{ng} / \mu \mathrm{l}$ Aroclor $^{\oplus} 1260$ was added to individual vials containing $0.50 \mathrm{~g}$ of AMTS. After the time displayed in Figure 1, samples were extracted and analyzed.

\section{Aroclor ${ }^{\circledast}$ degradation in contaminated paint chips}

A $0.8 \mathrm{~g}$ aliquot of AMTS was added to $0.15 \mathrm{~g}$ of industrial paint chips contaminated with a mixture of Aroclor $^{\oplus} 1248$ and 1260. After the time displayed in Table 1, the mixture of AMTS and paint chips were extracted and analyzed.

\section{Remediation of painted surface}

Approximately $100 \mathrm{mg}$ of Aroclor ${ }^{\oplus} 1254$ was added to $0.182 \mathrm{~kg}$ of Olympic ${ }^{\circ}$ fast hide with ultra semi-gloss paint. Three coats of paint were applied in $3.5 \mathrm{~cm}^{2} \mathrm{sec}-$ tions to two concrete blocks with a 24-hour drying period in between each coat. One block was treated with the NMTS and sealed while the other was left untreated as a control. Both blocks were sampled in triplicate after three and seven days. A $12.7 \mathrm{~mm}$ masonry drill bit was used to sample the concrete at two depths, $0 \mathrm{~mm}-8 \mathrm{~mm}$

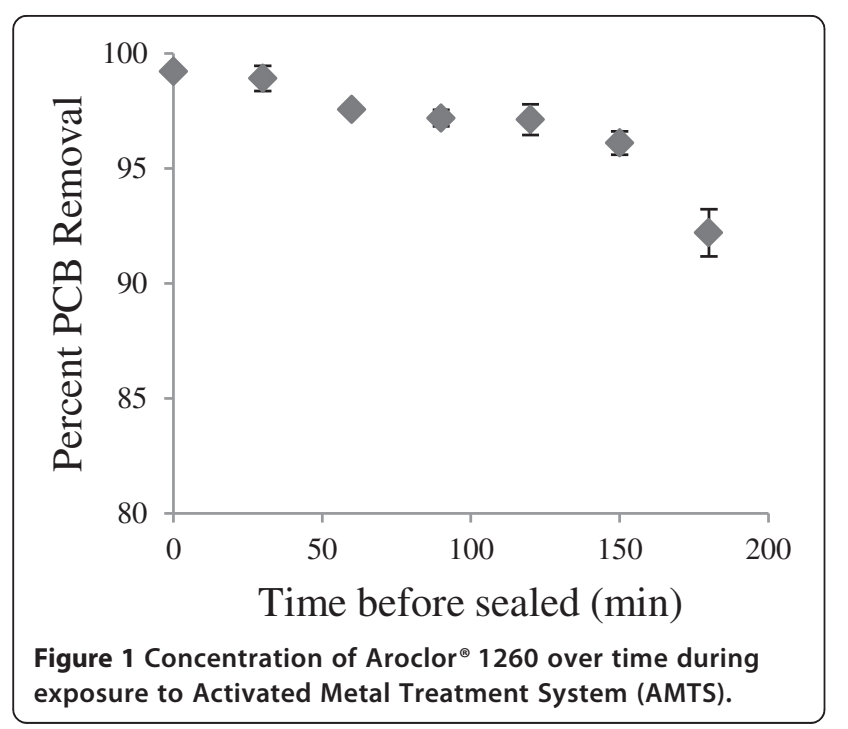

Table 1 PCB concentrations of industrial paint chip samples reacting with AMTS for 1 and 3 weeks

\begin{tabular}{cccc}
\hline Sample location \# & $\begin{array}{c}\text { Initial } \\
\text { concentration } \\
\text { (mg/Kg) }\end{array}$ & $\begin{array}{c}\text { 7 Day } \\
\text { concentration } \\
\text { ( } \mathbf{m g} / \mathbf{K g})\end{array}$ & $\begin{array}{c}\mathbf{3} \text { Week } \\
\text { concentration } \\
\text { (mg/Kg) }\end{array}$ \\
\hline 1 & $1390 \pm 152$ & $392 \pm 31.0$ & $42.6 \pm 23.5$ \\
2 & $831 \pm 42.0$ & $433 \pm 136$ & $51.2 \pm 15.5$ \\
3 & $2290 \pm 132$ & $491 \pm 155$ & $104 \pm 21.0$ \\
4 & $2397 \pm 16.2$ & & $52.3 \pm 5.77$ \\
5 & $2780 \pm 88.5$ & & $55.7 \pm 9.01$ \\
6 & $4540 \pm 181$ & & $385 \pm 43.0$ \\
7 & $1000 \pm 42.0$ & & $21.6 \pm 0.30$ \\
8 & $1380 \pm 79.0$ & & $42.0 \pm 28.8$ \\
\hline
\end{tabular}

and $8 \mathrm{~mm}-18 \mathrm{~mm}$ respectively. The paint and concrete were extracted and analyzed for PCBs.

\section{$P C B$ removal based on solvent evaporation}

PCB-laden paint, made by combining $15 \mathrm{mg}$ of $\mathrm{PCB}$ congener 151 with $0.073 \mathrm{~kg}$ of Olympic ${ }^{\oplus}$ paint, was applied to an aluminum surface in $2 \mathrm{~cm}^{2}$ areas and allowed to dry. A $3 \mathrm{~cm}^{2}$ area of NMTS was applied to each paint sample and was sealed with a vinyl polymer in thirty minute intervals. The amount of time that the NMTS remained exposed to ambient conditions before being sealed is displayed in Figure 2. The painted aluminum surfaces were extracted and analyzed for PCBs three days after the initial application.

\section{$P C B$ extraction and analysis}

Samples were extracted in $10.00 \mathrm{ml}$ of toluene using ultrasonic extraction [14]. Samples were centrifuged and the supernatants were subjected to a sulfuric acid/ permanganate clean-up [15]. Analysis was done in duplicate, unless stated otherwise, utilizing a Perkin

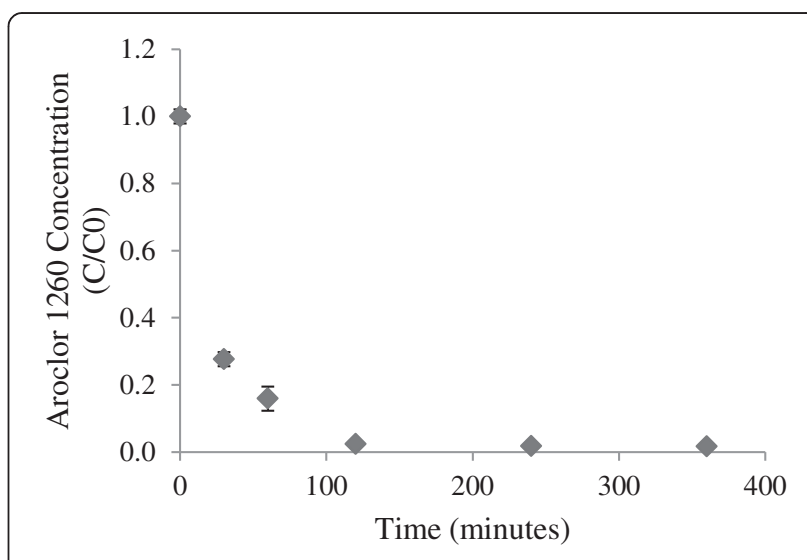

Figure 2 Percent PCB removal from paint relative to the amount of time passed before sealing the treatment system. 
Elmer AutoSystem XL GC/FID/ECD outfitted with a 30 m Restek Rtx- 5 column ( 0.25 mm ID, 0.25 um df). The temperature was ramped from $120^{\circ} \mathrm{C}$ to $300^{\circ} \mathrm{C}$. Aroclor concentrations were quantified by summing the area of five characteristic peaks in the mixture [16].

\section{Results \& discussion}

\section{Aroclor $^{\circledR}$ degradation through AMTS}

Figure 1 shows the degradation that occurred within the delivery system containing the hydrodechlorination reaction components, bulking agents, and paint softener. The AMTS degraded the majority of the peaks used for Aroclor 1260 quantification within 120 minutes supporting the claim that the treatment technology is a suitable matrix for significant PCB degradation. This timeframe is optimistic considering Single congener PCB-151 (2, $2^{\prime}, 3,5,5^{\prime}, 6$ - $\left.\mathrm{PCB}\right)$ has been reported in literature to degrade in the simpler matrix of ethanol, acetic acid, and magnesium within an hour [11]. The degradation is fast considering other popular techniques, like bioremediation, can take over 120 days to dechlorinate higher chlorinated PCB congeners by only $67 \%[17,18]$. Description of components and preparation of the treatment system are described in Additional file 1 and Additional file 2: Figure S1.

\section{Aroclor $^{\circledast}$ degradation in contaminated paint chips}

Analyzing paint samples is often challenging as great variations in PCB concentrations can occur, even within small test areas, due to the weathering of the paint, past renovations, and inconsistent paint applications [4]. The degradation of PCBs in paint chips can be seen in Table 1. Paint chips were sampled from structural materials and machine parts at eight locations of an aged manufacturing facility. Three samples were extracted after seven days of exposure to AMTS at which point approximately $21-52 \%$ of the original PCB concentration remained. Samples from all of the locations were extracted after three weeks of exposure to AMTS at which point approximately $2-8 \%$ of the original PCB concentration remained. Other degradation techniques reported to have been used on Aroclor contaminated paint require extreme conditions like high temperatures and pressures [19].

\section{Remediation of painted surface}

An analysis of the treatment system's ability to remove PCBs from painted porous material was conducted on concrete. After three days of treatment, approximately $73 \%$ of the PCBs in the paint were removed by the NMTS which rose to $76 \%$ removal at the end of day seven. Regarding the penetration into the concrete, Figure 3a and $3 \mathrm{~b}$ show that at three and seven days, fewer PCBs were detected in the treated concrete at both depths tested. As opposed to the PCBs being pushed further into the material during remediation, the NMTS removed PCBs that were there as a result of the original painting process. During the sampling, an effort was made to ensure that all paint was removed from the surface before the concrete was sampled. However, the variation in PCB concentrations for the untreated concrete at a depth of $0-8 \mathrm{~mm}$ on day three may be due to a flake of paint contaminating the sample. This small scale experiment simulates a field study where PCBs leached into concrete from nearby contaminated building material. The remediation technique described in the literature involved grinding down the top, and most concentrated, layer of the concrete to remove the contaminant [20]. Although both techniques enable the building to remain intact, our study demonstrates that NMTS can remove the leached PCBs during the treatment of the point source while avoiding further contamination to the surrounding environment.

\section{PCB removal based on solvent evaporation}

Treating large structures with AMTS/NMTS may require an extended time period between the application of the treatment system and the application of the sealant. The impact of a prolonged delay between the treatment application and the sealing process regarding $\mathrm{PCB}$ removal capability was analyzed. Figure 2 displays the percentage of PCB removal relative to the amount of time samples were exposed to ambient conditions before
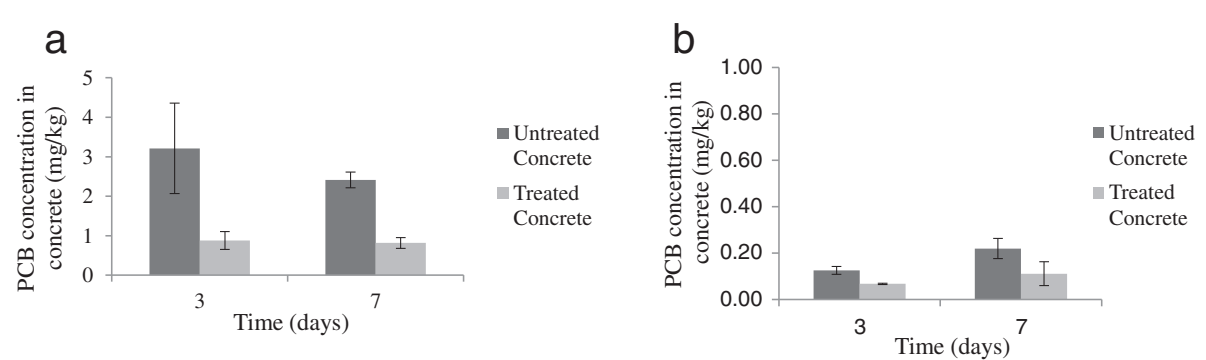

Figure 3 PCB concentration in concrete over time at various depths. (a) Concrete $0 \mathrm{~mm}-8 \mathrm{~mm}$ below the surface (b) Concrete $8 \mathrm{~mm}-18 \mathrm{~mm}$ below the surface. 
being sealed. It demonstrates that after three hours of exposure to ambient conditions, resulting in a $36 \%$ loss of solvent mass described in the Additional file 3 and Additional file 4: Figure S2, the NMTS maintained the ability to remove over $90 \%$ of the PCBs in the paint which is comparable to the reported extraction efficiencies of PCBs in soil [21]. Therefore, on a large scale, the time it would take to apply the treatment system to an entire wall/structure and the time it would take to seal the system would not greatly inhibit PCB removal.

\section{Conclusion}

The analysis of the treatment systems attests to the fact that the Activated Metal Treatment System (AMTS) and Non Metal Treatment System (NMTS) are feasible remediation options. Aroclor mixtures in solution and paint chips displayed significant degradation in the treatment system when activated with magnesium and acidified ethanol. Applied to painted porous materials, the treatment system decreased trace amounts of PCBs below the painted surface. A vinyl polymer sealant was used to minimize solvent loss and encourage PCB removal. Even when the time between the application and the sealing process was extended (simulating the treatment needs of large structures) high treatment efficiency was achieved. The information provided could eliminate the need to demolish and transport contaminated structures by providing a quick cost effective remediation technology. Once under the regulatory action limit, treated materials would be able to be repainted, used again, or resold.

\section{Additional files}

\section{Additional file 1: Treatment system components and preparation.}

This information describes how to prepare the treatment system described in the report. It is accompanied by Additional file 2: Figure S1.

Additional file 2: Figure S1. Schematic diagram to describe the production NMTS and AMTS.

Additional file 3: Evaporation rate as a function of surface area. This information describes and analyses data that observed the evaporation rate of the solvent system as a function of surface area of the treatment system. It is accompanied by Additional file 4: Figure S2.

Additional file 4: Figure S2. Percent solvent loss over time for samples with a surface area to mass ratio of $\Delta 3.6 \mathrm{~cm}^{2} / \mathrm{g}, \Delta 1.8 \mathrm{~cm}^{2} / \mathrm{g}$, and $\Delta 1.3 \mathrm{~cm}^{2} / \mathrm{g}$.

\section{Abbreviations}

(PCBs): Polychlorinated biphenyls; (AMTS): Activated metal treatment system; (NMTS): Non-metal treatment system; (EPA): Environmental Protection Agency; (GC): Gas chromatograph; (FID): Flame ionization detector; (ECD): Electron capture detector.

\section{Competing interests}

The United States of America as represented by the Administrator of the National Aeronautics and Space Administration holds the rights to the patent. CC, JQ, and CY are listed as co-inventors on the patent. $\mathrm{JQ}$ is a NASA employee but as a government employee, does not receive remuneration for intellectual property discoveries. The other authors do not receive reimbursements, fees, funding, or salary or any other financial benefit from this intellectual property.

The authors declare that they have no competing interests.

\section{Authors' contributions}

$C C, J Q$, and $C Y$ assisted in the conception/design of the technology and edited the manuscript. CY participated in the experimental design, the analysis of results, and the drafting of the manuscript. ES lead the laboratory studies, sample extraction and analysis of results as well as the drafting, writing and revising of the manuscript. MG assisted in the experimentation portion of the laboratory studies, sample extraction, analysis of results and editing of the manuscript. All authors read and approved the final manuscript.

\section{Acknowledgements}

The authors would like to thank the Environmental Security Technology Certification Program (ESTCP) for funding this research along with Geosyntec for their additional support.

\section{Author details}

'Department of Chemistry, University of Central Florida, 4000 Central Florida Blvd, Orlando, FL 32816-2366, USA. ${ }^{2}$ John Jay College of Criminal Justice, 899 Tenth Avenue, New York, NY 10019, USA. ${ }^{3}$ National Aeronautics and Space Administration, Kennedy Space Center, Florida 32899, USA.

Received: 26 August 2013 Accepted: 19 February 2014 Published: 6 March 2014

\section{References}

1. Hopf NB, Ruder AM, Succop P: Background levels of polychlorinated biphenyls in the U.S. population. Sci Total Environ 2009, 407:6109-6119.

2. Ter Schure AFH, Larsson P, Agrell C, Boon JP: Atmospheric transport of polybrominated diphenyl ethers and polychlorinated biphenyls to the Baltic Sea. Environ Sci Technol 2004, 38:1282-1287.

3. Andersson $\mathrm{M}$, Ottesen RT, Volden T: Building materials as a source of PCB pollution in Bergen, Norway. Sci Total Environ 2004, 325:139-144.

4. Jartun M, Ottesen RT, Steinnes E, Volden T: Painted surfaces: important sources of polychlorinated biphenyls (PCBs) contamination to the urban and marine environment. Environ Pollut 2008, 157:295-302.

5. Jartun M, Ottesen RT, Volden T, Lundkvist Q: Local sources of polychlorinated biphenyls (PCB) in Russian and Norwegian settlements on Spitsbergen Island, Norway. J Toxicol Environ Health A 2009, 72:284-294.

6. Agarwal S, Al-Abed SR, Dionysiou DD: A feasibility study on Pd/Mg application in historically contaminated sediments and PCB spiked substrates. J Hazard Mater 2009, 172:1156-1162.

7. U.S. Congress: Toxic substances control act. In Public Law 94-469; 1976

8. Kastanek F, Kastanek P: Combined decontamination processes for wastes containing PCBs. J Hazard Mater 2005, 117:185-205.

9. Kuusisto $\mathrm{S}$, Lindroos O, Rantio T, Priha E, Tuhkanen T: PCB-contaminated dust on indoor surfaces: health risks and acceptable surface concentrations in residential and occupational settings. Chemosphere 2007, 67:1194-1201.

10. Elie MR, Clausen CA, Geiger CL: Reduction of benzo[a]pyrene with acid-activated magnesium metal in ethanol: a possible application for environmental remediation. J Hazard Mater 2012, 203-204:77-85.

11. Maloney P, DeVor R, Novaes-Card S, Saitta E, Quinn J, Clausen CA, Geiger CL: Dechlorination of polychlorinated biphenyls using magnesium and acidified alcohols. J Hazard Mater 2011, 187:235-240.

12. Saitta EKH: Laboratory Studies to Field Evaluation: Remediation of Polychlorinated Biphenyl Contaminated Painted Surfaces Through the use of Activated Metal Treatment Systems. PhD thesis. University of Central Florida, Chemistry Department; 2010.

13. Quinn J, Clausen C, Geiger CL, Coon C, Berger CM, Filipek LB, Milum KM: Removal of PCB and other halogenated organic contaminants found in ex situ structures. US patent US7582682 B2 2007.

14. U. S. Environmental Protection Agency: Method 3550C Ultrasonic Extraction. EPA; 2007. Available: http://www.epa.gov/epawaste/hazard/testmethods/ sw846/pdfs/3550c.pdf. [4 April 2012].

15. U. S. Environmental Protection Agency: Method 3665A Sulfuric Acid/ Permanganate Cleanup. EPA; 1996. Available: http://www.epa.gov/epawaste/ hazard/testmethods/sw846/pdfs/3665a.pdf. [4 April 2012]. 
16. U. S. Environmental Protection Agency: Method $8082 \mathrm{~A}$ Polychlorinated Biphenyls (PCBs) by Gas Chromatography). EPA; 2007. Available: http://www.epa.gov/epawaste/hazard/testmethods/sw846/pdfs/8082a.pdf. [4 April 2012].

17. Shanquan W, Jianzhong H: Dechlorination of commercial PCBs and other multiple halogenated compounds by a sediment-free culture containing dehalococcoides and dehalobacter. Environ Sci Technol 2013, 47:10526-10534.

18. Gomes HI, Dias-Ferreira C, Ribeiro AB: Overview of in situ and ex situ remediation technologies for PCB-contaminated soils and sediments and obstacles for full-scale application. Sci Total Environ 2013, 445:237-260.

19. Kubatova A, Herman J, Steckler TS, De Veij M, Miller DJ, Klunder EB, Wai CM, Hawthorne SB: Subcritical (hot/liquid) water dechlorination of PCBs (Aroclor 1254) with metal additives and in waste paint. Environ Sci Technol 2003, 37:5757-5762.

20. Sundahl M, Sikander E, Ek-Olaussen B, Hjorthage A, Rosell L, Tornevall M: Determinations of PCB within a project to develop cleanup methods for PCB-containing elastic sealant used in outdoor joints between concrete blocks in buildings. J Environ Monit 1999, 14:383-387.

21. Paul N, Shubhen K, Qunhui L, Wander T, Adriana P, Virgil F: Solvent extraction and tandem dechlorination for decontamination of soil. Chemosphere 2001, 43:485-491.

doi:10.1186/2052-336X-12-57

Cite this article as: Saitta et al: Laboratory evaluation of a prospective remediation method for PCB-contaminated paint. Journal of Environmental Health Science \& Engineering 2014 12:57.

\section{Submit your next manuscript to BioMed Central and take full advantage of:}

- Convenient online submission

- Thorough peer review

- No space constraints or color figure charges

- Immediate publication on acceptance

- Inclusion in PubMed, CAS, Scopus and Google Scholar

- Research which is freely available for redistribution 